\title{
2 \\ El Financiamiento de las Cooperativas en las legislaciones de los países del Cono Sur Americano
}

\author{
Dante Cracogna
}

\section{Introducción}

Este estudio está orientado a analizar críticamente las disposiciones contenidas en la legislación sobre cooperativas vigentes en países del llamado Cono Sur americano en materia del financiamiento de estas entidades. Cabe, entonces, formular inicialmente algunas precisiones acerca de su alcance geográfico y de contenido.

En primer lugar debe señalarse que por países del Cono Sur en este contexto se alude concretamente, y por orden alfabético, a los siguientes seis países ubicados en el extremo sur del Continente sudamericano: Argentina, Bolivia, Brasil, Chile, Paraguay y Uruguay. El agrupamiento obedece al propósito de incluir dentro del estudio a los cuatro países que integran el Mercosur (Argentina, Brasil, Paraguay y Uruguay) más los dos países vinculados con dicho Tratado mediante acuerdos especiales (llamados «acuerdos de $4+1 »$ ): Bolivia y Chile.

En segundo término, debe precisarse que el enfoque se centra en las leyes específicas sobre cooperativas vigentes en los seis países, a saber: Ley de Cooperativas N. 20.377 de Argentina (1973); Ley General de Sociedades Cooperativas de Bolivia (1958); Ley de Sociedades Cooperativas N. ${ }^{\circ} 5764$ de Brasil (1971) y disposiciones del nuevo Código Civil vigente desde enero de 2003; Ley General de Cooperativas

1 En rigor, cuando se habla del Cono Sur no se incluye a Bolivia ni a Brasil, pues el primero integra la región andina y el segundo, por su magnitud geográfica y su ubicación, no encuadra exactamente en ninguna de las subregiones del Continente. Por otra parte, si bien Chile suele incluirse dentro del Cono Sur, es también un país andino. 
de Chile (con las modificaciones incorporadas por la ley 19.832 del 4.11.2002); Ley de Cooperativas N. ${ }^{\circ} 438$ de Paraguay (1994) y leyes 10.761 sobre cooperativas de producción y consumo (1946), 14.827 sobre cooperativas agroindustriales (1978), 15.645 de cooperativas agrarias (1984) y 13.728 en materia de cooperativas de vivienda (texto ordenado 1998) de Uruguay². En adelante, todas las citas legales que se efectúan están referidas a las leyes indicadas, salvo que se formule expresamente alguna salvedad. Vale decir que no se tratan otras disposiciones legales que pudieran tener alguna incidencia sobre la materia objeto del estudio ni tampoco se hace referencia específica a las cooperativas de ahorro y crédito cuyas particulares características las suelen sujetar a regímenes especiales ${ }^{3}$.

Por otra parte, debe tenerse presente que existen proyectos de reforma de la legislación sobre cooperativas en varios de los países considerados, los cuales han alcanzado diferentes grados de avance. Por ejemplo, en Brasil, hay tres proyectos de ley en trámite parlamentario desde hace varios años ${ }^{4}$; en Uruguay hace tiempo se viene estudiando la sanción de una ley general de cooperativas que supere la actual diversidad de leyes existente en ese país, prácticamente única en el Continente ${ }^{5}$; en Bolivia se proyecta una nueva ley que actualice la vigente, una de las más antiguas de la región. Estos proyectos - cuya suerte definitiva es incierta - no son tenidos en cuenta a efectos del análisis.

Por fin, ha de señalarse que una noción amplia de financiamiento comprende tanto el pasivo como el patrimonio neto; es decir todos los recursos de distinta índole necesarios para cubrir el activo. Sin embargo, el desarrollo del tema en este trabajo se circunscribe -básicamente- a los componentes del patrimonio neto, es decir el capital y las reservas, si bien también se hace alguna referencia a ciertas formas

2 Cabe señalar que al presente (marzo de 2003) se cuentan entre las leyes de cooperativas del Cono Sur tanto la más antigua de América Latina (Bolivia, 1958) como la más moderna (Chile, 2002).

3 Sin embargo - por el interés del tema- se hará una breve mención de la Ley uruguaya 17.613 de Fortalecimiento del Sistema Bancario, sancionada a fines de 2002, que alude a las cooperativas llamadas de intermediación financiera.

4 Cfr. Guilherme KRUEGER, «Informe sobre o estado actual da legislaçao cooperativa e a regência legal das cooperativas», Régimen legal de las cooperativas en los países del MERCOSUR, Intercoop, Buenos Aires, 2003, pág. 51.

5 Sergio ReYes LAVEGa y Danilo GutiéRREz, "Situación de la legislación cooperativa uruguaya», Régimen legal de las cooperativas en los países del MERCOSUR, cit., pág. 118 y ss. 
de endeudamiento que se caracterizan por ser diferentes del pasivo financiero o comercial corriente.

Por lo tanto, la estructura del trabajo consta de un análisis del tratamiento del capital y de las reservas en las distintas legislaciones nacionales, tratando de perfilar sus rasgos comunes y sus diferencias. Luego se hace una mención de las distintas modalidades de endeudamiento y finalmente se ensayan algunas conclusiones de carácter general.

\section{El capital cooperativo}

El capital es la forma de financiamiento por excelencia, no solamente de las cooperativas sino toda organización empresarial cualquiera que sea su forma jurídica societaria o asociativa. En sentido estricto consiste en el aporte que realizan los socios -en cualquier forma jurídica societaria de que se trate- con miras a lograr el objeto social. Es lo que se suele llamar "capital de riesgo» pues se trata de la inversión genuina de los socios que constituye la garantía de los terceros que contratan con la sociedad.

De allí que sea necesario distinguirlo claramente de otras nociones de capital que tienen un significado más amplio, como sinónimo de financiamiento, o diverso como, por ejemplo, capital de giro. En general, estas últimas y otras varias, son nociones que tienen que ver con el lenguaje de la economía o de la administración de empresas, en tanto que la noción de capital que se emplea en este trabajo está referida a su sentido propiamente jurídico.

Con los alcances indicados se analiza a continuación el tratamiento del capital en las legislaciones de la región.

a) Características: las leyes de la región, en general, coinciden en establecer que el capital es variable e ilimitado (Argentina, art. $2^{\circ}$, incs. 1 y 2; Brasil, art. 4. ${ }^{\circ}$, II, y art. 1094, I del nuevo Código Civil; Paraguay, art. 5. inc. c; Bolivia, art. 796; Chile, art. 25; Uruguay,

6 La ley boliviana llama «Fondo de Operaciones» al capital, pero incluye elementos heterogéneos dentro de él, tales como las donaciones, privilegios y cesión de derechos, otorgados por personas naturales o jurídicas» y «el valor de los créditos bancarios o de cualquier otro tipo» (art. 75). 
Ley 10.761, art. 3 y Ley 15.645, art. 18) lo cual resulta congruente con el principio de asociación voluntaria y abierta ${ }^{7}$ y constituye una sustancial diferencia con las sociedades comerciales en las cuales el capital está determinado en el contrato social y su modificación se halla sujeta a especiales requisitos ${ }^{8}$.

Por otra parte, igualmente consistente con los principios cooperativos es la generalizada disposición legal que establece que todos los socios cuentan con un solo voto, cualquiera sea el número de aportaciones con que cuenten (principio del gobierno democrático). Así sucede en Argentina (art. 2. ${ }^{\circ}$, inc. 3); Brasil (art. 4. ${ }^{\circ}, \mathrm{V}$ ); Bolivia (art. 1. ${ }^{\circ}$, inc. 2); Paraguay (art. 4, inc. b); Chile (art. 1. ${ }^{\circ}, 2^{\prime}$ párrafo); Uruguay: Ley 10.761 (art. 5); Ley 14.827 (art. 5); Ley 15.645 (art. 29), Ley 13.728 (art. 115, inc. b) ${ }^{9}$.

b) Capital mínimo: no se exige capital mínimo en ninguno de los países, con excepción de Chile, cuya ley establece que el capital será variable e ilimitado "a partir del mínimo que fijen sus estatutos» (art. 25) ${ }^{10}$. Este aspecto constituye una debilidad de las cooperativas puesto que las limita en sus posibilidades de giro previsible a la vez que no ofrece a los terceros mínimas garantías de certeza en cuanto al capital propio ${ }^{11}$. No obstante, corresponde señalar que algunas cooperativas se encuentran obligadas a contar con un capital mínimo legalmente establecido en razón de su objeto social específico, como

7 Cuando se hace referencia a los principios cooperativos se entiende que son los contenidos en la Declaración de Identidad Cooperativa aprobada por la Alianza Cooperativa Internacional en su Congreso del Centenario, Manchester 1995 (Cfr. ACl, Los principios cooperativos para el Siglo XXI, Intercoop, Buenos Aires, 1996, passim).

8 La naturaleza del capital cooperativo y sus principales notas caracterizantes, con especial referencia a la legislación argentina, se encuentran tratadas en Dante CRACOGNA, «El capital en las cooperativas», La Información, Buenos Aires, T. LXI, pág. 667 y ss.

9 Sin embargo, prácticamente todas las leyes permiten, como también lo hace la Declaración de Identidad Cooperativa, que en las cooperativas que no sean de primer grado el derecho de voto no sea igualitario, siempre que se organice de manera que evite el predominio de alguna cooperativa sobre las demás.

10 La Ley 10.761 de Uruguay dice que el estatuto fija el monto del «capital inicial» (art. 6) pero no habla de capital mínimo, que es una noción diferente. De igual manera sucede con la Ley 15.645 de ese país (art. 5, inc. $3^{\circ}{ }^{\circ}$ ).

11 Refiriéndose a la legislación uruguaya Siegbert Rippe critica que no se fijen mínimos de capital social, lo cual, sumado a la propias limitaciones de los socios, se traduce en bajas aportaciones individuales ( $\mathrm{El}$ capital en las cooperativas (El caso uruguayo)», Boletín de la Asociación Internacional de Derecho Cooperativo, N. ${ }^{\circ} 35$, Deusto, 2001, pág. 68). 
sucede con las de seguros y los bancos, en los países donde está permitido que las cooperativas realicen estas actividades ${ }^{12}$.

El nuevo Código Civil brasileño introdujo una variante de significativa importancia en esta materia, pues consagró la posibilidad —única en la legislación regional- de que las cooperativas prescindan de capital social (art. 1094, I).

c) Responsabilidad: la responsabilidad de los socios por las deudas de la cooperativa constituye la manera de brindar garantía a los terceros. En esta materia las soluciones legales son variadas. Mantienen la responsabilidad de los socios limitada al monto de sus aportes suscriptos Argentina (art. 2. ${ }^{\circ}$, inc. 11); Paraguay (art. 27); Chile (art. 27); Uruguay, Ley 10.761 (art. 2). En cambio admiten otras formas de responsabilidad —además de la limitada - las leyes de Brasil (art. 12) que permite también la ilimitada13; de Bolivia que reconoce también la suplementada ${ }^{14}$, al igual que la Ley 15.645 (art. 7) de Uruguay y la Ley 14.827 (art. 7) del mismo país que permite las tres variantes: limitada, suplementada e ilimitada.

Parecería que la flexibilidad legal — que deja librado a cada cooperativa elegir el régimen de responsabilidad que mejor le convieneresulta una medida adecuada, aunque la tendencia general se orienta a la limitación de la responsabilidad.

d) División: el capital aportado por los socios se divide en partes iguales que reciben diferentes denominaciones y cuyo valor deben fijar los respectivos estatutos: cuotas sociales (Argentina, art. 24), cuotas partes, con valor no superior al mayor salario mínimo vigente (Brasil, art. 24); certificados de aportación (Paraguay, art. 38; Bolivia, art. 76);

12 Tal es el caso de Argentina, donde las leyes de entidades financieras (21.526) y de entidades de seguros (20.091) permiten que las cooperativas incursionen en estas actividades pero con una exigencia de capital mínimo idéntica a la de las otras formas jurídicas admitidas.

13 En esta materia el nuevo Código Civil mantiene ambas clases de responsabilidad (art. 1095 , par. $1 .^{\circ}$ y $2 .^{\circ}$ ) pero en el caso de la responsabilidad limitada la extiende a los perjuicios verificados en las operaciones sociales en proporción a la participación del socio en dichas operaciones.

14 El «suplemento» de responsabilidad de los socios puede establecerse en un determinado múltiplo del monto de sus cuotas sociales suscriptas o bien en una prorrata por las deudas sociales hasta una cantidad determinada fijada en el estatuto. Este último es el caso de la ley boliviana, en tanto que el primero es el de la Ley 14.827 de cooperativas agroindustriales de Uruguay. 
aportes de capital (Chile, art. 25)15; partes sociales (Uruguay, Ley 10.761, art. 5; Ley 15.645, art. 18); partes sociales con valor mínimo fijado por ley y reajustable (Uruguay, Ley 13.728, art. 119 inc. A).

e) Títulos: en general las leyes prescriben que los títulos que representan los aportes de los socios serán nominativos y solamente transferibles entre quienes son socios o reúnan las condiciones para serlo, con acuerdo del órgano de administración (Argentina, art. 24; Brasil, art. 26; Paraguay, art. 38; Bolivia, art. 76; Chile, art. 29; Uruguay, Ley 10.761, art. 4). Esta característica de los títulos o certificados se compadece con el carácter eminentemente personal que reviste la asociación a una cooperativa, en consonancia con la definición de cooperativa que brinda la Declaración de Identidad Cooperativa ${ }^{16}$.

La Ley boliviana establece expresamente que no son documentos mercantiles y que no pueden circular en mercados de valores (art. 77), lo cual resulta obvio por cuanto siendo el ingreso de socios libre y pudiéndose emitir certificados sin restricción por ser variable e ilimitado el capital, no tendría sentido su negociación en mercados bursátiles.

f) Formación e incremento: el capital se forma e incrementa mediante los aportes que realizan los socios al momento de constituir la cooperativa o bien cuando ingresan a ella posteriormente. Sin perjuicio de ello pueden realizar aportes adicionales cuando ya reúnen la calidad de socios, sea voluntariamente o por exigencia estatutaria o asamblearia, según los casos.

En general, las leyes exigen que los estatutos establezcan el capital mínimo que cada socio debe suscribir (Argentina, art. $8 .^{\circ}$, incs. 3 y 6 ; Brasil, art. 21, III; Bolivia, art. 66, inc. c; Chile, art. 25).

15 La ley chilena dice que «La participación de los socios en el patrimonio se expresará en cuotas de participación, cuyo valor será el que resulte de la suma del valor de sus aportes de capital, más las reservas voluntarias y más o menos, según corresponda, el ajuste monetario señalado en el inc. tercero del art. 30 de la presente ley y los excedentes o pérdidas existentes, dividido por el total de cuotas de participación emitida al cierre del período» (art. 24, tercer párrafo). De manera que son nociones diferentes las de «aporte» y de «cuota de participación», pues esta última comprende los aportes y otros conceptos.

16 Dice la definición de la $\mathrm{ACl}$ : «Una cooperativa es una asociación autónoma de personas que se unen voluntariamente para satisfacer sus necesidades y aspiraciones económicas, sociales y culturales comunes por medio de una empresa de propiedad conjunta democráticamente gestionada». 
La ley argentina autoriza que el estatuto prevea un procedimiento para la formación e incremento del capital en proporción con el uso real o potencial de los servicios sociales (art. 27). Vale decir que en una cooperativa agraria, por ejemplo, podría establecerse que cada asociado aportará capital según la cantidad de producto que comercializa a través de la cooperativa o conforme con la cantidad de hectáreas que tenga destinadas a producción, en la inteligencia que los servicios (reales o potenciales) que requiera de la cooperativa son proporcionales a dichas cantidades. Brasil permite también dicho sistema

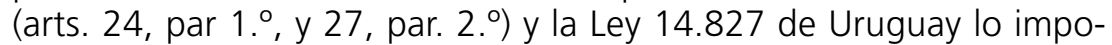
ne (art. 4). Este mecanismo ha probado ser eficaz para adecuar el capital de las cooperativas al nivel de sus necesidades y distribuir equitativamente entre los socios la obligación de aportarlo ${ }^{17}$.

Se admite que los excedentes anuales que corresponden a los socios sean distribuidos en aportes de capital por decisión de la asamblea (Argentina, art. 44; Paraguay, art. 45). A su vez, la ley de Bolivia autoriza que el estatuto destine un porcentaje de los excedentes a aumentar el Fondo de Operaciones (art. 75, inc. 5. ${ }^{\circ}$ ). En Chile el excedente puede distribuirse en cuotas de participación (art. 36). Esta posibilidad de capitalizar los excedentes constituye una forma sencilla y fácil de aumentar el capital pues no exige esfuerzo financiero a los socios. Suele ser la fuente más corriente de capitalización de las cooperativas por lo cual la obtención de excedentes favorece su consolidación patrimonial.

g) Límite de capital por socio: por lo general las leyes se limitan a establecer el capital mínimo que cada socio debe aportar, sin determinar límite máximo. Ello se explica por cuanto la circunstancia de contar con mayor capital no modifica los derechos del socio y en caso

17 El Proyecto de Ley Marco para las Cooperativas de América Latina aprobado por la Organización de las Cooperativas de América en 1988 prevé expresamente este sistema (art. 37) destacando en su justificación la experiencia favorable recogida en diferentes países que lo han aplicado (OCA, América Cooperativa, Documento Especial N. ${ }^{\circ} 3$, Bogotá, 1988). Sin embargo, con relación al caso brasileño —donde la aplicación de este sistema se halla considerablemente extendido entre las cooperativas agrariasVergilio F. PERIUs formula una apreciación crítica basada en la participación preponderante que los socios con más capital asumen en la cooperativa y, por otra parte, en el incentivo que introduce para desviar la entrega de producción a la cooperativa a fin de evitar la retención de la correspondiente proporción de capital («Tratamento do Capital nas Sociedades Cooperativas Brasileiras», Boletín de la Asociación Internacional de Derecho Cooperativo, N. ${ }^{\circ}$ 35, Deusto, 2001, págs. 90-91). 
de retiro todos los socios se encuentran sujetos a las mismas disposiciones comunes para el reembolso de sus aportes.

No obstante, la ley de Brasil prescribe que ningún socio puede suscribir más de un tercio del capital total, salvo que se tratara de capital proporcional (art. 24, par. $1^{\circ}{ }^{\circ}$ ) o de personas jurídicas en las cooperativas de servicios públicos (art. 24, par. 2. ${ }^{\circ}$ ). La ley de Bolivia prohíbe exigir más de un certificado de aportación a los nuevos socios (art. 10), pero no fija límite máximo a las aportaciones voluntarias. La ley chilena dispone que ningún socio puede tener más del $20 \%$ del capital de las cooperativas en general, ni más del $10 \%$ en las de ahorro y crédito (art. 22). El obvio fundamento de la limitación legal reside en que la concentración del capital en pocos socios puede amenazar el funcionamiento normal de la cooperativa, pero la contrapartida de ese argumento es la necesidad de capital, por lo común apremiante, que las cooperativas en general suelen padecer.

h) Integración: el pago o desembolso de las aportaciones de capital suscriptas por los socios se halla sujeto a exigencias de forma y de tiempo que las leyes determinan. La ley argentina establece que pueden aportarse bienes determinados y susceptibles de ejecución forzada; cuando de trate de aportes no dinerarios su valuación debe ser aprobada por la asamblea (art. 28). También la ley brasileña admite el aporte en bienes sujeto a valuación por la asamblea (art. 27). Por su parte, la ley paraguaya admite que el capital se integre en dinero, otro bienes o servicios, exigiendo que estos últimos revistan carácter imprescindible para la cooperativa; la valuación está a cargo del órgano de administración (art. 39). La ley de Bolivia también permite aportes en efectivo, bienes, derechos o trabajo, con valuación acordada por la asamblea (art. 76) y la ley chilena reconoce aportes no dinerarios, valuados conforme con las disposiciones del estatuto (art. 12, inc. c). Las leyes uruguayas 14.827 y 15.645 también permiten aportes en dinero, especie o trabajo (arts. 12 y 19, respectivamente), en tanto que la ley 13.728 dispone que los trabajos de autoconstrucción y ayuda mutua en las cooperativas de vivienda serán avaluados para la cuota social (art. 121).

En materia de plazo existen distintas pautas legales: mínimo del $5 \%$ al contado y resto hasta en cinco años desde la suscripción (Argentina, art. 25); en cuotas, conforme lo disponga el estatuto (Brasil, art. 25); pago del porcentaje que establezca el Reglamento (Bolivia, art. 66, inc. d); el estatuto establece el plazo de integración de los aportes (Chile, art. 12, inc. c). En los demás casos, corresponderá al 
estatuto fijar el plazo de integración como parte de las obligaciones de los socios.

La ley paraguaya determina que los intereses y retornos ${ }^{18}$ que correspondan a socios que tuvieran aportes de capital pendientes de integración serán aplicados al pago del saldo pendiente (art. 40).

En ciertos casos la legislación autoriza que la cooperativa pueda exigir el cumplimiento de los importes pendientes de integración por la vía del juicio ejecutivo. Así lo prevé expresamente la ley chilena, estableciendo como título ejecutivo la copia del acta del consejo de administración (art. 34). Por su parte, las leyes uruguayas 14.827 y 15.645 establecen que los saldos deudores de los socios, en general, constituyen título ejecutivo (arts. 9 y 16, respectivamente), por lo que quedarían comprendidos también los importes pendientes de integración.

i) Prenda o embargo: en las sociedades comerciales es posible constituir prenda sobre las acciones o bien hacerlas objeto de embargo por parte de los acreedores de sus titulares. Habida cuenta del carácter intuitu personae que revisten las cooperativas, este tema es motivo de distintas opiniones y de soluciones legales también diferentes, aunque mayoritariamente orientadas a negar la posibilidad de prenda o embargo sobre los certificados de aportación.

La ley argentina contempla la posibilidad de prenda y embargo, pero establece que tales medidas no afectan los derechos del socio (art. 34). Vale decir que sólo tendrán efectos patrimoniales limitando la propiedad de los aportes y sus frutos civiles, pero no impiden que el socio pueda seguir utilizando los servicios de la cooperativa y participando en sus órganos sociales. La ley de Paraguay dispone que el capital del socio es inembargable, salvo por cobro judicial de la propia cooperativa (art. 35) ${ }^{19}$.

j) Revalúo: en países con larga tradición inflacionaria como los de la región, el revalúo de las aportaciones de capital constituye un

18 La palabra «retorno» es empleada en varias leyes de la región para indicar la porción del excedente que se devuelve al socio en proporción a sus operaciones con las cooperativa.

19 Cabe señalar que, en rigor, cuando existen débitos y créditos recíprocos entre la cooperativa y el socio debe operarse la compensación de deudas, hasta límite que ella alcance, por lo que no se advierte que pueda tener lugar el embargo judicial de las acciones del socio por parte de la cooperativa. 
problema de especial importancia. En efecto, la erosión producida por la inflación deteriora tanto los valores de los activos no monetarios que aparecen en los balances de las cooperativas como los valores del capital que son su correlato contable. De allí que este tema sea generalmente motivo de disposiciones legales orientadas a resolver el problema. En algunos casos la solución consiste en remitir a la aplicación de normas generales para todo tipo de empresa, en tanto que en otros las leyes de cooperativas contienen disposiciones específicas sobre la materia.

La ley argentina dispone que las cooperativas pueden revaluar sus activos conforme con la reglamentación que dicte la autoridad de aplicación (art. 45), la cual sigue los lineamientos comunes a toda clase de empresas y permite que el saldo resultante del revalúo sea distribuido en cuotas sociales a los socios tomando en cuenta la antigüedad de sus aportes o sea destinado a una cuenta de reserva ${ }^{20}$. Similar disposición contiene la ley paraguaya (art. 50). La ley chilena establece que la corrección monetaria de activos y pasivos se efectuará de conformidad con el régimen general, aunque se prevé que la reglamentación de la ley contendrá normas especiales sobre el tema (art. 30). La ley uruguaya 15.645 dispone que los estatutos pueden establecer el reajuste de las partes sociales fijando las bases respectivas (art. 18).

En suma, el revalúo o actualización del valor de las cuotas sociales surge como una necesidad derivada de los efectos de la inflación ${ }^{21}$. Sin embargo, en ciertos casos se admite que el saldo contable en lugar de ser capitalizado a los socios sea destinado a reserva como una manera de consolidar el patrimonio social.

k) Interés: las leyes de los distintos países son coincidentes en prescribir que el capital aportado por los socios puede recibir solamente un interés limitado, el cual se abona con los excedentes resultantes del balance anual de tal suerte que si no existen excedentes no se paga interés alguno.

20 El revalúo, conforme con la legislación argentina, está tratado en Dante CRACOGNA, «Balance ajustado y capitalización en las cooperativas», Derecho Fiscal, Buenos Aires, T. XL, pág. 172 y ss.

21 Sostiene Waldirio Bulgarelu que la corrección monetaria no es un plus que se acrece al socio sino un minus que se evita (As sociedades cooperativas e a sua disciplina jurídica, Renovar, Río de Janeiro, 1998, pág. 2225). 
En Argentina la tasa de interés que se puede pagar al capital no puede exceder en más de un punto a la que cobra el Banco de la Nación en operaciones de descuento (art. 42 , inc. $4 .^{\circ}$ ) pero la ley autoriza que no se pague interés alguno (art. 2. ${ }^{\circ}$, inc. 4). También en Brasil se fija una tasa limitada de interés (art. 24, par. $3^{\circ}$ ) $^{22}$. En Paraguay el interés que se pague a los certificados de aportación no podrá exceder del promedio ponderado de las tasas pasivas abonadas por el sistema bancario y financiero nacional para los depósitos a plazo. Conforme con la ley boliviana solamente se reconoce un interés limitado a las aportaciones extraordinarias (art. $1 .^{\circ}$, inc. 6). En Chile el estatuto puede establecer el pago de interés al capital (art. 36).

La limitación del interés al capital constituye uno de los principios cooperativos reconocidos en la Declaración de Identidad Cooperativa, por lo que su recepción en las leyes de cooperativas resulta congruente con naturaleza propia de estas entidades ${ }^{23}$.

I) Reembolso: la devolución o reembolso del capital aportado por los socios puede tener lugar por diferentes motivos: por renuncia del socio; por exclusión del socio resuelta por la cooperativa o por disolución de la cooperativa. El reembolso plantea diversos problemas, de los cuales son principales, por su incidencia económico financiera en el desenvolvimiento de la cooperativa: el valor de las aportaciones a reembolsar y el plazo dentro del cual se hará efectiva la devolución.

En cuanto al valor de los aportes a devolver la ley argentina dispone que sólo será el valor nominal en cualquier caso (art. 36) puesto que las reservas son irrepartibles (art. 2. ${ }^{\circ}$, inc. 12). Lo mismo dispone la ley paraguaya (arts. 34 y 99, inc. b). Según la ley brasileña, en caso de liquidación sólo se devuelve el valor de las cuotas partes (art. 73). La ley de Bolivia, por su parte, remite el régimen de devolución del capital a lo que determine la ley reglamentarla (arts. 71 y 72), pero dice que en caso de disolución se devolverá el valor de los certificados de aportación (art. 104, inc. d). La ley chilena dispone que el estatuto

22 El nuevo Código Civil autoriza que se pague un interés fijo al capital realizado (art. 1094, VII).

23 El 3.er principio reza: «Los socios contribuyen equitativamente a la formación del capital de su cooperativa y lo gestionan democráticamente ... Los socios suelen recibir una compensación limitada, si acaso alguna, sobre el capital suscripto como condición para asociarse...» Como se advierte, el enunciado del principio resulta rico en diferentes matices. 
determinará las modalidades relativas a la devolución de los aportes de capital efectuados por los socios (art. 12, inc. d) y prevé que en caso de liquidación se reembolsará a cada socio el valor actualizado de sus cuotas de participación (at. 37)24. También la Ley 14.827 de Uruguay dispone que en caso de disolución se devuelve a los socios el importe de su capital actualizado (art. 6. ${ }^{\circ}$, inc. 10).

Con relación al plazo para la devolución de los aportes en caso de renuncia la ley argentina lo deja librado al estatuto (art. $8 .^{\circ}$, inc. 6) pero autoriza a limitar el reembolso total de cada ejercicio al $5 \%$ del capital integrado, atendiendo las solicitudes por orden de antigüedad y pasando al ejercicio siguiente las que no pudieran ser atendidas (art. 31). Las cuotas sociales pendientes de reembolso devengan un interés equivalente al $50 \%$ de la tasa correspondiente a depósitos de plazo fijo (art. 32) 25 . La ley paraguaya establece que mientras no se haga efectiva la devolución el capital continuará devengando el interés que fije la asamblea al distribuir el excedente del ejercicio en que se produjo la cesación del socio (art. 34). Conforme con la ley chilena, el estatuto puede poner limitaciones al derecho de renuncia (art. 12, inc. d), lo cual supone demorar el reembolso del capital, pero por otra parte se autoriza el retiro parcial de los aportes, siempre de acuerdo con lo previsto por el estatuto (art. 35). A su vez, las leyes 14.827 y 15.645 de Uruguay autorizan que los estatutos establezcan un período de permanencia obligatoria de hasta cinco años contados desde el ingreso del socio (arts. 8 y 12, respectivamente).

Las restricciones en la devolución de los aportes o la exigencia de permanecer como socio durante un cierto lapso contribuyen a evitar el efecto negativo que puede producir sobre las finanzas de la cooperativa el retiro masivo de socios o de aquéllos que cuentan con mayor cantidad de capital.

24 La norma de la ley chilena que habla del reembolso del valor actualizado de los aportes puede considerarse común a las demás legislaciones que prevén el revalúo o corrección monetaria de los aportes pues, aunque no lo digan expresamente, lo que se devuelve a los socios en caso de liquidación es valor nominal de los aportes, en el que está incluida la correspondiente actualización o ajuste.

25 Frente a las graves dificultades de orden financiero que a algunas cooperativas les provocaba la devolución del 5\% anual de su capital integrado, el Instituto Nacional de Acción Cooperativa dictó la resolución N. $1027 / 94$ que autoriza que la asamblea, con el voto de los dos tercios de los presentes, suspenda el reembolso de cuotas sociales por un plazo de hasta tres ejercicios. 


\section{Las reservas}

Las reservas constituyen una parte del patrimonio social que amplía y complementa el capital. A diferencia del capital, las reservas no son aportadas por los socios sino que se originan en resultados no distribuidos $^{26}$. Las reservas contribuyen, pues, a consolidar el patrimonio cooperativo y su existencia no genera costo alguno toda vez que no hay que retribuirlas con interés como suele ocurrir con el capital. Por otra parte, siendo su fuente el excedente que arroje la gestión económica de la cooperativa, la existencia de las reservas y su incremento dependen de que efectivamente se produzcan resultados superavitarios.

En las cooperativas las reservas adquieren un significado especial por cuanto se trata de recursos que forman una verdadera propiedad social — de la propia cooperativa- y no de los socios en particular ${ }^{27}$. Dichos recursos, cuyo uso no tiene costo, se aplican estrictamente al cumplimiento del objeto social y de esa manera posibilitan la prestación de mejores servicios y ayudan a fortalecer patrimonial mente a la cooperativa y potenciar su desarrollo.

En suma, las reservas constituyen un financiamiento de gran importancia para las cooperativas, tanto por el volumen que ellas pueden alcanzar como por tratarse de recursos de uso gratuito ${ }^{28}$.

26 Podría decirse que las reservas, en general, constituyen un aporte indirecto de los socios cuando provienen de excedentes no distribuidos, puesto que se trata de recursos sustraídos a la apropiación por parte de aquéllos. Sin embargo, existen otras reservas que provienen de excedentes no producidos por los socios, como la que se forman con excedentes que provienen de servicios prestados a no socios $u$ originados en ventas de bienes del activo.

27 La irrepartibilidad de las reservas tiene dilatada tradición en el movimiento cooperativo internacional. Sin embargo, fue muy debatida con motivo de la reformulación de los principios cooperativos realizada en el Congreso del Centenario de la $\mathrm{ACl}$, donde finalmente fue incluida. Adrián CelayA UllibarRI, señala que la afectación de los excedentes a reservas no atribuibles a los socios «es un elemento de evidente desincentivación de la constitución de cooperativas y de la generación de beneficios». («Criterios básicos para una regulación legal del capital en las sociedades cooperativas», Boletín de la Asociación Internacional de Derecho Cooperativo, N. ${ }^{\circ} 35$, Deusto, 2001, pág. 13). También Vergilio F. PERIus le dirige una crítica al tema con relación a la experiencia brasileña, («Tratamento do Capital nas Sociedades Cooperativas Brasileiras», cit., págs. 89-90).

28 Sobre el significado y la importancia de las reservas en las cooperativas puede verse: Alfredo A. Althaus, "Los fondos sociales de la cooperativa», Derecho Cooperativo. Tendencias actuales en Latinoamérica y la Comunidad Económica Europea, OCA, Bogotá, 1993, pág. 152 y ss. 
a) Fuente: las reservas provienen del resultado favorable producido por la gestión económica. Por lo común se forman con parte del excedente repartible a los socios. Así lo disponen la ley argentina (art. 42, inc. $1^{\circ}$ ); la ley brasileña (art. 28, I); la ley paraguaya (art. 42, inc. a); la ley boliviana (art. 82, Inc. $1 .^{\circ}$ ) y la ley chilena (arts. 25 y 36). En Uruguay lo disponen las leyes 10.761 (art. 10), 14.827 (art. 20) y 15.645 (art. 21). Sin embargo, también pueden formarse con excedentes no repartibles a los socios como sucede en Argentina con aquellos que derivan de la prestación de servicios a no socios (art. 42, último párrafo); igualmente dispone el decreto reglamentario de la Ley 10.761 de Uruguay, si bien también autoriza destinar ese excedente a obras de progreso social (art. 9).

Adicionalmente, conforme se desprende del primer párrafo del art. 42 de la ley argentina, también se destinan a reservas los excedentes que no provengan de la diferencia entre el costo y el precio de los servicios prestados a los socios, como sería la diferencia entre el valor de origen o el valor contable de un bien del activo y su valor de realización. También el saldo proveniente del revalúo de bienes del activo puede ser destinado en todo o en parte a reservas (Paraguay, art. 50-1 Argentina, art. 45 y Res. INAES 1150/02).

b) Clases: existen distintas clases de reservas según la determinación de cada una de las leyes nacionales o de sus respectivas reglamentaciones. No obstante, con carácter general, pueden clasificarse en obligatorias y voluntarias o facultativas. Las primeras son impuestas por la ley con carácter imperativo ${ }^{29}$, en tanto que las segundas dependen de la voluntad de cada cooperativa expresada en su estatuto o en la asamblea.

La ley argentina exige la formación de varias reservas obligatorias pero no autoriza constituir otras por voluntad de la cooperativa, protegiendo de esa manera el derecho de los socios al excedente que originaron con sus operaciones. Este criterio restrictivo contrasta con el de las otras leyes de la región que permiten la constitución de reservas facultativas, sea por disposición del estatuto o por resolución de la asamblea: Brasil (art. 28, par. 1. ${ }^{\circ}$ ); Paraguay (art. 42, inc. c); Bolivia (art. 82, inc. $4 .^{\circ}$ ); Chile (art. 12 inc. d), si bien en este país las reservas

29 De allí que en varios países de la región — como Argentina, Chile y Paraguayse la denomine «reserva legal». 
voluntarias no pueden superar el $15 \%$ del patrimonio, salvo en las cooperativas abiertas de vivienda y en las de ahorro y crédito (art. 36). Las leyes 14.827 y 15.645 de Uruguay facultan a continuar con la formación de la reserva legal una vez que cesa su obligatoriedad por haber alcanzado un determinado porcentaje del capital (arts. 20 y 21, respectivamente).

Resulta evidente que una permisión amplia de formación de reservas permite ampliar el patrimonio social y contar con recursos de financiamiento sin costo, por lo que aparece como una política aconsejable. Así lo prevé el Proyecto de Ley Marco (art. 51).

c) Formación: en general, las leyes de los países de la región establecen que un determinado porcentaje del excedente anual debe ser destinado a la formación de la reserva obligatoria. En ciertos casos, dicha afectación del excedente cesa cuando la reserva acumulada alcanza a un determinado del capital social, en tanto que en otros continúa indefinidamente o bien se permite que continúe por voluntad de la cooperativa.

En Argentina la ley manda destinar a reserva obligatoria el $5 \%$ de los excedentes repartibles, sin limitación alguna en cuanto al monto que alcance (art. 42, inc. $1^{\circ}$ ). En Brasil debe destinarse a reserva el $10 \%$, por lo menos, de los excedentes (art. 28, I). En Paraguay, también el $10 \%$ hasta alcanzar el $25 \%$, por lo menos, del capital integrado (art. 42, inc. a). En Uruguay, según Ley 10.761, el $15 \%$ hasta igualar el capital, luego el $10 \%$ hasta triplicar el capital, después de lo cual cesa la obligación de aumentar esta reserva (art. 10). Similar sistema establece la Ley 14.827 (art. 20). La Ley 15.645, por su parte, impone el $15 \%$ hasta igualar el capital, luego permite reducirla al $10 \%$ (art. 21). En Bolivia debe destinarse a reservas el $10 \%$ de los excedentes (art. 82, inc. $1 .^{\circ}$ ) hasta alcanzar, al menos, el $25 \%$ del activo (art. 83, inc. a). La ley chilena prescribe que las cooperativas abiertas de vivienda y las de ahorro y crédito deben dedicar a reserva un porcentaje no inferior al $20 \%$ de los remanentes anuales (art. 36).

d) Destino: las reservas — salvo el caso de afectación legal específica a otra finalidad - se destinan a cubrir los quebrantos que pudiera arrojar el balance anual, de manera de mantener incólume el capital. Por ello, en caso de ser utilizadas deben ser reconstituidas al nivel en que se encontraban antes de su utilización; entretanto no pueden distribuirse excedentes. Así lo disponen la ley argentina (art. 43) y la ley boliviana (art. 84). La ley paraguaya, a su vez, se limita a establecer 
que la reserva se destina a enjugar la pérdida del ejercicio (art. 43), al igual que la ley brasileña (art. 89).

Habida cuenta de la función que cumplen las reservas, cuya acumulación consolida el patrimonio social y permite la prestación de mejores servicios, algunas leyes prohíben expresamente que se cobre a los nuevos socios que ingresan a la cooperativa una prima a título de compensación por las reservas. Así disponen las leyes de Argentina (art. 18) y de Brasil (art. 37, II).

e) Indivisibilidad: el tercer principio de la Declaración de Identidad Cooperativa dice que la cooperativas «destinan los excedentes a todos o alguno de los siguientes fines: desarrollo de la cooperativa, posiblemente mediante la constitución de reservas de las cuales una parte al menos debe ser indivisible ...». Vale decir que la indivisibilidad o irrepartibilidad de todas o parte de las reservas ha sido reconocida con jerarquía de principio. Esta característica se halla incorporada en todas las leyes de los países de la región, con excepción de Chile y Bolivia.

En el caso de Argentina, la irrepartibilidad de las reservas está expresamente establecida (art. 2, inc. 12), por lo tanto, en caso de retiro o disolución los socios sólo tienen derecho al valor nominal del las cuotas sociales, deducidas las pérdidas que les correspondiera soportar (art. 36) y si de la liquidación resultara un sobrante una vez devuelto el valor nominal de las cuotas sociales, será destinado al Fisco para promoción de las cooperativas (arts. 94, 95 y 101). También la ley brasileña establece la indivisibilidad de las reservas (arts. 4, VIII y 68, VI), la cual es ratificada por el nuevo Código Civil aun para el caso disolución (art. 1094, VIII). Asimismo en Paraguay está consagrada la irrepartibilidad de las reservas (arts. 5, inc. c, y 44); disponiéndose que el saldo de la liquidación tendrá el destino que fije el estatuto (art. 99, inc. c). La Ley 15.645 de Uruguay prescribe que en caso de retiro o disolución los socios sólo tienen derecho al valor de sus aportes, con el reajuste que correspondiera, y que el remanente de la liquidación se destinará al Ministerio de Agricultura y Pesca para fomento del cooperativismo agrario (arts. 14 y 39).

La ley boliviana dispone que en caso de liquidación se debe «distribuir el remanente siguiendo las mismas reglas adoptadas en el reparto de los excedentes de percepción» (art. 104, inc. f), lo cual implica que las reservas se distribuyen. Por su parte, la ley chilena contiene una disposición de similar tenor, pero de mayor amplitud: «En caso de 
disolución de la cooperativa, una vez absorbidas las eventuales pérdidas, pagadas las deudas y reembolsado a cada socio el valor actualizado de sus cuotas de participación, las reservas legales y cualesquiera otros excedentes resultantes, se distribuirán entre lo socios a prorrata de sus cuotas de participación» (art. 37).

\section{Otras formas de financiamiento}

El capital aportado por los socios y las reservas constituyen las fuentes del autofinanciamiento cooperativo, pues se trata de recursos que integran el patrimonio neto de la cooperativa. Además de ellos existen diversas otras formas de financiamiento que no integran el patrimonio neto sino que hacen parte del pasivo, es decir del endeudamiento de índole comercial o financiera. Las cooperativas en general pueden acudir a todas esas formas de financiamiento en igualdad de condiciones con las demás organizaciones empresarias ${ }^{30}$.

Sin embargo, existen algunos mecanismos específicos - siempre de carácter facultativo- previstos por las leyes de cooperativas de los distintos países de la región que, por su naturaleza, resulta de interés mencionar.

La ley boliviana contempla los llamados «certificados de participación» que consisten en aportaciones realizadas por personas ajenas a la cooperativa, los cuales devengan un interés no superior al que fije el estatuto, el reglamento o el mercado bancario (art. 78).

En Paraguay las cooperativas y sus centrales (organizaciones de integración económica) se hallan autorizadas para emitir «bonos de inversión» con fines de financiamiento productivo (art. 37). El Reglamento de la ley (art. 31) exige la autorización del Instituto Nacional de Cooperativismo (INCOOP), previo dictamen del Banco Central, cuando la oferta se haga al público ${ }^{31}$.

La Ley 10.761 de Uruguay permite que las cooperativas puedan contraer «obligaciones» hasta el $40 \%$ de su capital realizado (art. 11l),

30 «El Proyecto de Ley Marco para las Cooperativas de América Latina prevé expresamente que las cooperativas podrán asumir todas las formas de pasivo» (art. 45).

31 Cfr. Antonio Bonzl, El Derecho Cooperativo en la Legislación Nacional y Comparada, Centro Editorial Paraguayo. Asunción, 1998, pág. 378. 
cuya emisión se halla sujeta a la intervención previa de la Inspección de Hacienda (art. 12, decreto reglamentario).

También la Ley 14.827 del mismo país prevé que si los estatutos lo contemplan, las cooperativas pueden emitir «obligaciones» hasta la mitad del capital efectivo, previa autorización del Poder Ejecutivo (art. 18). De manera similar, la Ley 15.645 dispone que pueden emitir «obligaciones o debentures» hasta la mitad del capital integrado más las reservas, con autorización del Ministerio de Agricultura y Pesca (art. 20)32.

El decreto reglamentario de la Ley 10.761 prevé asimismo la emisión de "acciones con interés», las cuales son nominativas y rescatables en cualquier momento por la cooperativa. La tasa de interés no puede superar la correspondiente a los títulos de la deuda nacional interna y se paga con los excedentes, una vez constituidas las reservas y distribuido a los socios el retorno que les correspondiera por sus operaciones (art. 13).

Similares «acciones con interés» se encuentran previstas en la Ley uruguaya 17.613 de Fortalecimiento del Sistema Bancario ${ }^{33}$, que permite a las cooperativas de intermediación financiera emitir dichos títulos, siempre que se hallen previstos por el estatuto, previa autorización del Banco Central del Uruguay. La ley dispone que estas acciones formarán parte del patrimonio de la cooperativa y serán nominativas, sin conferir derechos políticos a sus titulares. Su monto total no puede superar el $50 \%$ del capital y pueden ser rescatadas en cualquier momento. La asamblea fijará las condiciones de emisión, el plazo de suscripción y la tasa de interés (art. 12).

La ley brasileña autoriza que la asamblea resuelva crear «fondos rotatorios» con recursos destinados a fines específicos, fijando el modo de formación, aplicación y liquidación (art. 28, par. 1. ${ }^{\circ}$ ). Estos fondos, diferentes del capital rotatorio, son préstamos obligatorios de

32 Siegbert RIPPE critica los límites que imponen las leyes uruguayas pues, al ser reducido el capital de las cooperativas, resulta también limitada la posiblidad de obtener financiamiento suficiente por vía de las obligaciones negociables o debentures. Por otra parte, señala que la ley 16.749 de mercado de valores y obligaciones negociables facilita a las cooperativas a emitir obligaciones negociables sin establecer relaciones restrictivas con relación al capital social. («El Capital en las Cooperativas (El caso uruguayo)», cit., pág. 69 y nota 4).

33 Esta ley fue promulgada el 27.12.02 dentro del marco de la crisis por la que atravesaba el sistema financiero uruguayo en ese momento. 
los intereses y retornos que corresponden a los socios al final de cada ejercicio, los cuales se devuelven al cabo de un cierto plazo ${ }^{34}$.

En Argentina las cooperativas cuentan varios mecanismos de financiamiento adicionales a los corrientes. Por decisión de la asamblea pueden emitir «obligaciones negociables» con sujeción a las disposiciones de la ley general que regula la emisión de estos títulos por parte de distintos sujetos de derecho (Ley 23.576). Si dichas obligaciones negociables fueran de oferta pública es necesaria la conformidad de la Comisión Nacional de Valores. Asimismo - conforme con el decreto 289/90 - pueden emitir títulos en serie que tengan las mismas características y sean ofrecidos en forma genérica, siempre que no se confundan con otros títulos previstos en la legislación vigente ${ }^{35}$. Por último, el Instituto Nacional de Acción Cooperativa, autoridad de aplicación de la Ley de Cooperativas, dictó las resoluciones N. ${ }^{\circ}$ 349/95 y 593/99 en virtud de las cuales se autoriza a las cooperativas a emitir «títulos cooperativos de capitalización» que pueden ser suscriptos por los socios con un plazo no inferior a seis meses y una tasa de interés no superior al máximo permitido para el capital.

\section{Conclusiones}

Las cooperativas tienen una debilidad estructural para la captación de recursos de capital toda vez que, por su naturaleza, existen razones de principios que reducen el incentivo de sus socios por aumentar sus aportes, a saber: el gobierno democrático y la limitación del interés al capital ${ }^{36}$.

En la cooperativa el capital cumple la función meramente instrumental de posibilitar la prestación del servicio que constituye su objeto

34 Cfr. Dante Cracogna, «El tema del financiamiento en la legislación cooperativa subregional», La legislación cooperativa en el Mercosur. Anales del Primer Congreso de Legislación Cooperativa del Mercosur, Intercoop, Buenos Aires 1994, pág. 207.

35 Cfr. Alfredo A. Althaus, «Los fondos sociales de la cooperativa», cit., pág. 152.

36 Narciso PAZ CANALejo hace un interesante análisis de las limitaciones financieras de las cooperativas y comienza afirmando que la principal limitación de las cooperativas desde el punto de vista financiero es la derivada de la peculiar (y subordinada) posición del capital social en la estructura de la entidad, tanto si se contempla desde el punto de vista de los derechos económicos como analizada bajo la perspectiva de los derechos políticos del socio» (La sociedad cooperativa ante el reto de los mercados actuales. Un análisis no sólo jurídico, Ministerio de Trabajo y Asuntos Sociales, Madrid, 2002, pág. 103). 
social. Los socios suscriben e integran capital con esa única finalidad y normalmente lo hace en la medida estrictamente indispensable, sea por dificultad económica o por la referida falta de atractivo.

En un contexto económico globalizado y con fuerte tendencia a la concentración, la necesidad de recursos financieros que experimentan las cooperativas es, cuando menos, semejante a la de las demás empresas. Sin embargo, sus posibilidades de obtenerlos se presentan más limitadas, a veces no solamente en materia de capital sino también en cuanto al endeudamiento. Ello es así, entre otros motivos, por la variabilidad de su capital que reduce la garantía de los acreedores ${ }^{37}$.

Las apuntadas condiciones hacen necesario que la legislación contemple apropiadamente la situación de las cooperativas y les abra posibilidades de financiamiento que las habiliten para subsistir y desarrollarse dentro de un marco altamente competitivo. En tal sentido, deben tenerse en cuenta tanto los aspectos relativos a la formación del capital y las reservas como así también el acceso al endeudamiento en sus distintas formas ${ }^{38}$.

El análisis de la legislación de los países considerados permite advertir que el capital tiene un tratamiento sustancialmente similar en todos ellos, adecuado a los principios cooperativos. Sin embargo, en algunas leyes existen arbitrios que convendría extender a las demás, tales como el capital mínimo; el capital proporcional; la distribución de los excedentes en certificados de aportación; el aumento obligatorio del capital por parte de los socios bajo determinadas condiciones; la creación de aportaciones voluntarias con interés determinado y plazo de devolución; las formas adicionales de responsabilidad de los socios; un régimen adecuado para la devolución de las aportaciones ${ }^{39}$; etc.

37 Sin embargo, también debe mencionarse la falta de adecuada información o el prejuicio que en algunos medios económicos existe acerca de las cooperativas como sujetos calificados para ser titulares de crédito.

38 En este sentido deben tenerse las directrices encaminadas a crear un entorno propicio para el desarrollo de las cooperativas, contenidas en la resolución 56/114 de la asamblea de las Naciones Unidas del 18.1.02 como así también en la recomendación N. ${ }^{\circ} 193$ de la OIT sobre la promoción de las cooperativas.

39 Destaca Adrián Celaya UllibarRI la importancia que el tema del reembolso de las aportaciones reviste para la configuración del capital cooperativo. Puntualiza que deberían introducirse adecuaciones legales «que permitan a las tradicionales aportaciones cooperativas sustituir el derecho del socio al reembolso en caso de baja por otras opciones de reembolso, haciendo así posible la propia configuración global del Capital Social como Fondo de Capital estable e incentivado». («Criterios básicos para una regulación legal de capital en las sociedades cooperativas», cit., pág. 16). 
En cuanto a las reservas también pueden advertirse algunas medidas susceptibles de extenderse a otros países: la admisión de reservas voluntarias; la fijación de porcentajes significativos para la formación de las reservas obligatorias-, el destino a reservas de los excedentes que provienen de la prestación de servicios a no socios o de la realización de operaciones ajenas al objeto social; la ilimitación del monto de las reservas; la obligación de restituirlas cuando se hubieran utilizado, etc.

Por último, en materia de endeudamiento, además de admitirse con amplitud que las cooperativas asuman todas las formas de pasivo, deberían acogerse de manera expresa los mecanismos de financiación ya previstos en algunas legislaciones ${ }^{40}$ : emisión de obligaciones negociables a suscribir por socios o terceros; fondos rotatorios formados con excedentes o con un determinado porcentaje de las operaciones realizadas por los socios con la cooperativa; certificados de inversión cooperativa a suscribir por socios o extraños; acciones de terceros sin derechos políticos; ${ }^{41}$ etc.

En suma, la presencia cooperativa en el mercado actual y su posible desarrollo dependen —en buena medida - de la existencia y uso de adecuados y oportunos mecanismos de financiamiento, sin descuidar la eficiente administración y el apoyo de los socios a los que debe servir.

40 Resultan ilustrativas a este respecto las experiencias mencionadas por Kai ReHFELDT y Enea MAZzolı bajo el título «Nuevas formas de capitalización sin perder la naturaleza cooperativa. Acceso al mercado de capitales» en Crecimiento económico con desarrollo social. La experiencia cooperativa y el rol de sus empresas, Intercoop, Buenos Aires, 1997, pág. 93 y ss.

41 Cabe señalar que en algunos países europeos se ha avanzado en la adopción legal de la figura del «socio inversor», es decir socio no usuario con derechos políticos, lo cual es motivo de controversia. Resultan ilustrativos sobre este tema: Malcolm LYNCH - Ian SNAITH, «Report on the scope of non-user investor members of a European Cooperative Society, Boletín de la Asociación Internacional de Derecho Cooperativo, N. ${ }^{\circ} 26-27$, Deusto, mayo-diciembre 1996, pág. 15 y ss.; Hans-H. MüNKNER, «Go public and remain cooperative?», idem, pág. 63 y sS. y Dante CRACOGNA, «El régimen del capital en la proyectada reforma de la Ley Argentina de Cooperativas», idem, pág. 7 y ss. 